
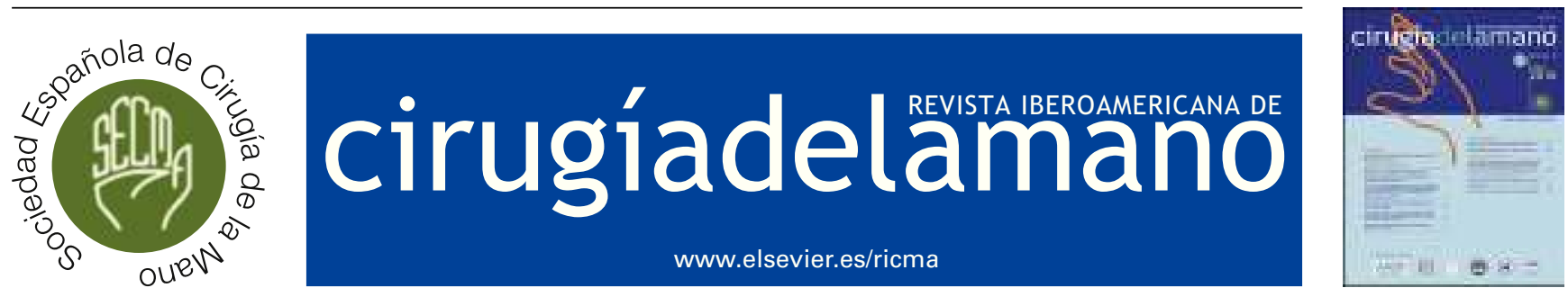

ARTÍCULO ORIGINAL

\title{
Tumor de células gigantes de la vaina tendinosa de la mano. Estudio de la epidemiología, eficacia de las pruebas de imagen en su diagnóstico y análisis de la recidiva
}

\author{
A. Orois Codesal*, J.A. Oteo Maldonado y P. Benavente
}

Servicio de Cirugía Ortopédica y Traumatología, Hospital Universitario de Fuenlabrada, Fuenlabrada, Madrid, España

Recibido el 17 de noviembre de 2015; aceptado el 29 de enero de 2016

Disponible en Internet el 7 de marzo de 2016

\section{PALABRAS CLAVE \\ Tumor de células \\ gigantes; \\ Eficacia de las \\ pruebas de imagen; \\ Recidiva}

\section{KEYWORDS}

Giant cell tumor;

Effectiveness of

imaging tests;

Recurrence

\begin{abstract}
Resumen
Objetivos: Conocer la capacidad diagnóstica de las diferentes pruebas de imagen empleadas en nuestro centro. Valorar si la distribución de las diferentes variables que definen la tumoración es la misma en los tumores con y sin recidiva.

Material y método: Se valoraron 54 casos de tumor de células gigantes de la vaina tendinosa de la mano. En todos se realizó una radiografía, en 19 ecografía y en 7 resonancia magnética. Los datos analizados fueron: sexo, edad, antecedente traumático, dedo afecto, localización, resultado de las pruebas de imagen, características anatomopatológicas de la tumoración (tamaño y número de nódulos), y presencia o no de recidiva.

Resultados: Se objetivó 1,7 mujeres por cada varón. La mano derecha y el segundo dedo fueron las localizaciones más frecuentes. Ninguna radiografía fue diagnóstica; la ecografía tuvo un valor predictivo positivo de $36,8 \%$ y la resonancia magnética de $71,4 \%$. Hubo 6 casos de recidiva, sin relación estadísticamente significativa entre la recidiva y el tamaño, el número de nódulos o la artrosis.

Conclusión: La resonancia magnética tiene una capacidad diagnóstica superior a la ecografía, y esta, superior a la radiografía simple. No se ha encontrado ninguna asociación estadísticamente significativa entre la recidiva de la lesión y los factores estudiados.

(C) 2016 SECMA. Publicado por Elsevier España, S.L.U. Este es un artículo Open Access bajo la licencia CC BY-NC-ND (http://creativecommons.org/licenses/by-nc-nd/4.0/).
\end{abstract}

Giant cell tumor of the tendon sheath of hand. Study of the epidemiology, effectiveness of imaging in the diagnosis and analysis of relapse

\section{Abstract}

Objectives: To determine the diagnostic accuracy of different imaging tests used in our Center. Assess whether the distribution of the different variables that define the tumor is the same as in the tumors with and without recurrence.

\footnotetext{
* Autor para correspondencia.

Correo electrónico: almudena.orois@salud.madrid.org (A. Orois Codesal).
} 
Methods: 54 cases of giant cell tumor of the tendon sheath of hand were evaluated. In all radiography it was performed, ultrasound in 19 cases and 7 MRI. The data analyzed were: sex, age, history of trauma, finger affection, location, results of imaging tests, pathologic features of the tumor (size and number of nodules), and presence or absence of recurrence.

Results: The female/male ratio was 1.7, right hand and the second finger were the most common sites. None was diagnostic radiography, ultrasound had a positive predictive value of $36.8 \%$ and $71.4 \%$ MRI. 6 cases of recurrence, with no statistically significant relationship between recurrence and the size, number of nodules or osteoarthritis.

Conclusion: MRI has superior diagnostic capability of ultrasound and ultrasound is superior to plain radiography in the diagnosis of GCT tendon sheath in hand.

The non-significant association with any recurrence of the rated factors does not mean that does not exist.

(C) 2016 SECMA. Published by Elsevier España, S.L.U. This is an open access article under the CC BY-NC-ND license (http://creativecommons.org/licenses/by-nc-nd/4.0/).

\section{Introducción}

El tumor de células gigantes es la segunda neoplasia benigna más común a nivel de la vaina tendinosa de los dedos, después del ganglión ${ }^{1,2}$, no existiendo acuerdo en relación con la etiología de la misma. Es más frecuente en mujeres, con 1,5-2 casos frente a 1 en varones ${ }^{3}$, típico en la tercera y la quinta décadas de la vida y afecta preferentemente al segundo y tercer dedos ${ }^{4-6}$. Se ha de establecer diagnóstico diferencial con los quistes sinoviales. La complicación más habitual es la recidiva, apreciándose hasta en un $45 \%$ de $\operatorname{casos}^{7,8}$.

Dada la alta incidencia de esta tumoración, resulta muy útil saber qué prueba de imagen es la más adecuada, por lo que se propone como primer objetivo de este estudio conocer la capacidad diagnóstica de las diferentes pruebas de imagen empleadas en nuestro centro (radiografía simple, ecografía con doppler y resonancia magnética). Así mismo, como segundo objetivo, se propone valorar si la distribución de las diferentes variables que definen la tumoración es la misma en los tumores con y sin recidiva.

\section{Material y método}

Se trata de un estudio descriptivo donde se valoraron 54 casos consecutivos (todos los intervenidos en nuestro centro desde enero de 2007 a diciembre de 2009), con el diagnóstico anatomopatológico posquirúrgico de tumor de células gigantes de la vaina tendinosa de la mano.

Todos los pacientes acudieron a la consulta del centro de especialidades con una radiografía simple de la zona afecta (anteroposterior y lateral) solicitada por el médico de atención primaria. Según el médico del servicio de Cirugía Ortopédica y Traumatología que valoraba cada paciente, se solicitaba o no otra prueba diagnóstica (en 19 casos una ecografía con doppler, y en 7 una resonancia magnética).

La cirugía se hizo con isquemia por elevación, realizando exéresis total de la tumoración, siendo remitida esta a anatomía patológica para estudio.

Los parámetros estudiados fueron los siguientes: sexo, edad, presencia de antecedente traumático, dedo afecto, localización en el dedo (volar/dorsal), resultado de las pruebas de imagen realizadas previas a la cirugía (radiografía simple, ecografía con doppler y resonancia magnética), artrosis, características anatomopatológicas de la tumoración (tamaño de la lesión definido por las longitudes craneocaudal, lateromedial y anteroposterior, y número de nódulos), y presencia o no de recidiva.

Las variables empleadas para el análisis de la recidiva fueron: tamaño de la lesión, número de nódulos y presencia o no de artrosis en la radiografía simple.

El análisis estadístico de los datos se llevó a cabo con el software SPSS 20.0 (IBM, Chicago, Illinois). Tras un análisis descriptivo inicial se realizó un estudio de las variables tamaño de la lesión, número de nódulos y presencia o no de artrosis en función de la aparición de recidiva. Se empleó la prueba no paramédica U de Mann-Whitney (dado que el número de casos de recidiva era menor de 10) para el estudio del tamaño de la lesión, y la prueba de Chi cuadrado (test exacto de Fisher cuando la frecuencia esperada era menor de 5 en más del $20 \%$ de las casillas, en tablas 2 por 2) para el análisis de la distribución de las variables número de nódulos y la artrosis (según radiografía simple). Además se calcularon los valores predictivos de las distintas pruebas de imagen.

\section{Resultados}

Los datos demográficos fueron los siguientes: 20 varones (37\%) y 34 mujeres (63\%), (1,7 mujeres por cada varón), con una edad media 46 años (entre 23 y 77 años).

En 7 casos (12\%) se refirió un traumatismo previo en la zona de la tumoración.

La localización más frecuente fue la mano derecha y el dedo más comúnmente comprometido fue el segundo, no apreciándose diferencias en relación con la posición del tumor en el dedo (tabla 1).

El tamaño medio de la tumoración fue de $1,47 \mathrm{~cm}$ craneocaudal, $1,08 \mathrm{~cm}$ lateromedial y $0,6 \mathrm{~cm}$ anteroposterior. El tumor fue uninodular en 51 casos y binodular en 3 .

En relación con las pruebas de imagen, ninguna radiografía fue diagnóstica; en 5 casos se apreció un claro aumento de partes blandas, en 10 casos se observó artrosis en las articulaciones interfalángicas, 2 de ellos en la proximal y 8 en la distal, teniendo 3 de las distales erosiones significativas. Por el contrario, con las otras técnicas sí que se consiguió el diagnóstico preoperatorio de algunos tumores: 
Tabla 1 Distribución de los casos, localización y recidivas

\begin{tabular}{|c|c|c|c|c|c|c|c|}
\hline \multirow[t]{2}{*}{ Localización } & \multicolumn{7}{|c|}{ Dedo } \\
\hline & $1 .^{\circ}$ & $2 .^{\circ}$ & $3 .^{\circ}$ & $4 .^{\circ}$ & $5 .^{\circ}$ & $\mathrm{n}$ & \\
\hline \multirow[t]{4}{*}{$\mathrm{FD}(\mathrm{n}=9)$} & Cubital & 0 & 1 & 0 & 0 & 0 & 1 \\
\hline & Dorsal & 0 & 2 & $2(1)^{a}$ & 0 & 0 & 4 \\
\hline & Radial & 0 & 1 & 0 & 0 & 0 & 1 \\
\hline & Volar & 1 & 2 & 0 & 0 & 0 & 3 \\
\hline \multirow[t]{4}{*}{ IFD $(n=13)$} & Cubital & 0 & 0 & 0 & 0 & 0 & 0 \\
\hline & Dorsal & 0 & 3 & 1 & 1 & $2(1)^{\mathrm{a}}$ & 7 \\
\hline & Radial & 0 & $2(1)^{a}$ & 1 & 0 & 0 & 3 \\
\hline & Volar & 0 & 1 & 1 & 0 & 1 & 3 \\
\hline \multirow[t]{4}{*}{$\mathrm{FI}(\mathrm{n}=3)$} & Cubital & 0 & 0 & 0 & 0 & 0 & 0 \\
\hline & Dorsal & 0 & 0 & 0 & 0 & 0 & 0 \\
\hline & Radial & 0 & 0 & 0 & 0 & 0 & 0 \\
\hline & Volar & 0 & 1 & 1 & $1^{\mathrm{a}}$ & 0 & 3 \\
\hline \multirow[t]{4}{*}{ IFP $(n=10)$} & Cubital & 2 & 0 & 1 & 0 & 0 & 3 \\
\hline & Dorsal & 2 & 1 & 0 & 0 & 0 & 3 \\
\hline & Radial & 0 & 1 & 1 & 0 & 0 & 2 \\
\hline & Volar & 2 & 0 & 0 & 0 & 0 & 2 \\
\hline \multirow[t]{4}{*}{$\operatorname{FP}(n=16)$} & Cubital & 1 & 1 & 0 & 0 & 1 & 3 \\
\hline & Dorsal & 3 & 0 & 1 & 1 & 1 & 6 \\
\hline & Radial & 0 & 1 & 0 & 0 & 0 & 1 \\
\hline & Volar & 0 & 4 & $2(1)^{a}$ & 0 & 0 & 6 \\
\hline \multirow[t]{5}{*}{$M F(n=3)$} & Cubital & 0 & 0 & 0 & 0 & 0 & 0 \\
\hline & Dorsal & 0 & 0 & 0 & 0 & 0 & 0 \\
\hline & Radial & 0 & 0 & 0 & 0 & 0 & 0 \\
\hline & Volar & 1 & 1 & 0 & 1 & 0 & 3 \\
\hline & $\mathrm{n}$ & 12 & 22 & 11 & 4 & 5 & 54 \\
\hline
\end{tabular}

FD: falange distal; Fl: falange intermedia; FP: falange proximal; IFD: articulación interfalángica distal; IFP: articulación interfalángica proximal; MF: articulación metacarpofalángica.

a Casillas correspondientes a las recidivas. Entre paréntesis el número de casos de recidivas del total.

la ecografía (fig. 1) tuvo un valor predictivo positivo de $36,8 \%$ (7/19), mientras que el de la resonancia magnética (fig. 2) fue del $71,4 \%(5 / 7)$.

Se diagnosticaron 6 casos de recidivas $(11,1 \%)$ (tabla 2$)$, no encontrándose una relación estadísticamente significativa entre la recidiva y las variables que definen el tamaño de la tumoración, el número de nódulos y la presencia de artrosis.

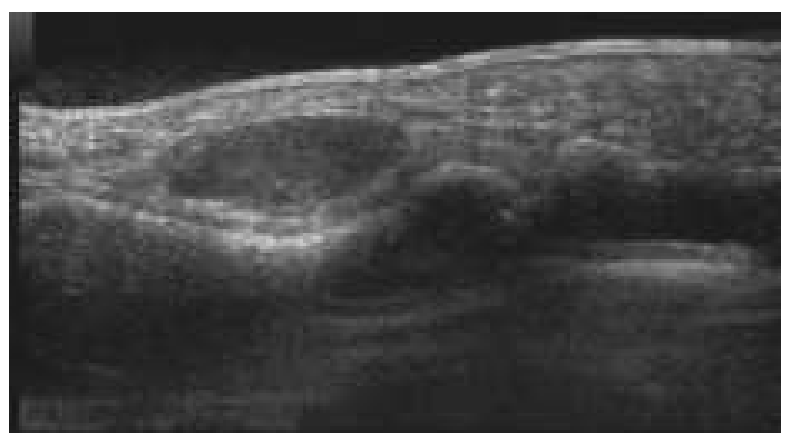

Figura 1 Sección sagital de ecografía de un tumor de células gigantes de la vaina tendinosa situado en la región volar de la falange proximal.

\section{Discusión}

Nuestros hallazgos epidemiológicos coinciden con lo publicado previamente; se da más frecuente en mujeres $(1,7 / 1)$, en la cuarta década de la vida, localizado en el segundo dedo, y con antecedente traumático en un $12 \%$ de los casos (se han publicado cifras de un $15 \%)^{2,3}$. Por el contrario, hemos observado una relación volar dorsal de $1 / 1$, mientras que se ha publicado que la localización volar es más frecuente en los 3 primeros dedos de la mano hasta en un $80 \%$ de los $\operatorname{casos}^{8}$.

En cuanto a los patrones descritos en la bibliografía sobre las alteraciones en la radiografía simple, especialmente la artrosis en articulación interfalángica distal, nuestros resultados son similares a artículos previos ${ }^{9-11}$.

Se sabe que el tumor de células gigantes de mano y muñeca es hipoecogénico ${ }^{12}$, con un aumento de vascularización, por lo que se ha considerado que la ecografía asociada con doppler podría aportar información diagnóstica sobre el mismo $^{13}$. En nuestra revisión la capacidad diagnóstica de la ecografía es baja a pesar de la mejoría técnica de los equipos, posiblemente porque se trata de una prueba observador dependiente ${ }^{14}$.

La presencia de hemosiderina y de abundante colágeno favorece el diagnóstico con resonancia magnética ${ }^{15}$, y se ha considerado como la prueba con el valor predictivo positivo 
Tabla 2 Características de los casos que recidivaron

\begin{tabular}{|c|c|c|c|c|c|c|c|}
\hline Dedo & Localización & Posición & Nódulos & Largo (mm) & Ancho $(\mathrm{mm})$ & Grosor (mm) & Erosiones \\
\hline $2 .^{\circ}$ & IFD & Radial & 1 & 15 & 10 & 5 & No \\
\hline $3 .^{\circ}$ & FD & Dorsal & 2 & 14 & 6 & 7 & Sí \\
\hline $3 .^{\circ}$ & FP & Volar & 1 & 25 & 18 & 6 & No \\
\hline $4 .^{\circ}$ & IFD & Dorsal & 1 & 7 & 5 & 4 & No \\
\hline $4 .^{\circ}$ & $\mathrm{FI}$ & Volar & 1 & 17 & 8 & 6 & No \\
\hline $5 .^{\circ}$ & IFD & Dorsal & 1 & 15 & 7 & 6 & Sí \\
\hline
\end{tabular}

FD: falange distal; FI: falange intermedia; FP: falange proximal; IFD: articulación interfalángica distal.

más alto para el estudio preoperatorio del tumor de células gigantes de la vaina tendinosa ${ }^{16}$, lo que se ha confirmado en nuestra revisión.

En nuestro estudio, el nivel de recidivas $(11,1 \%)$ es bastante inferior a lo publicado $(45 \%)$. Se han descrito

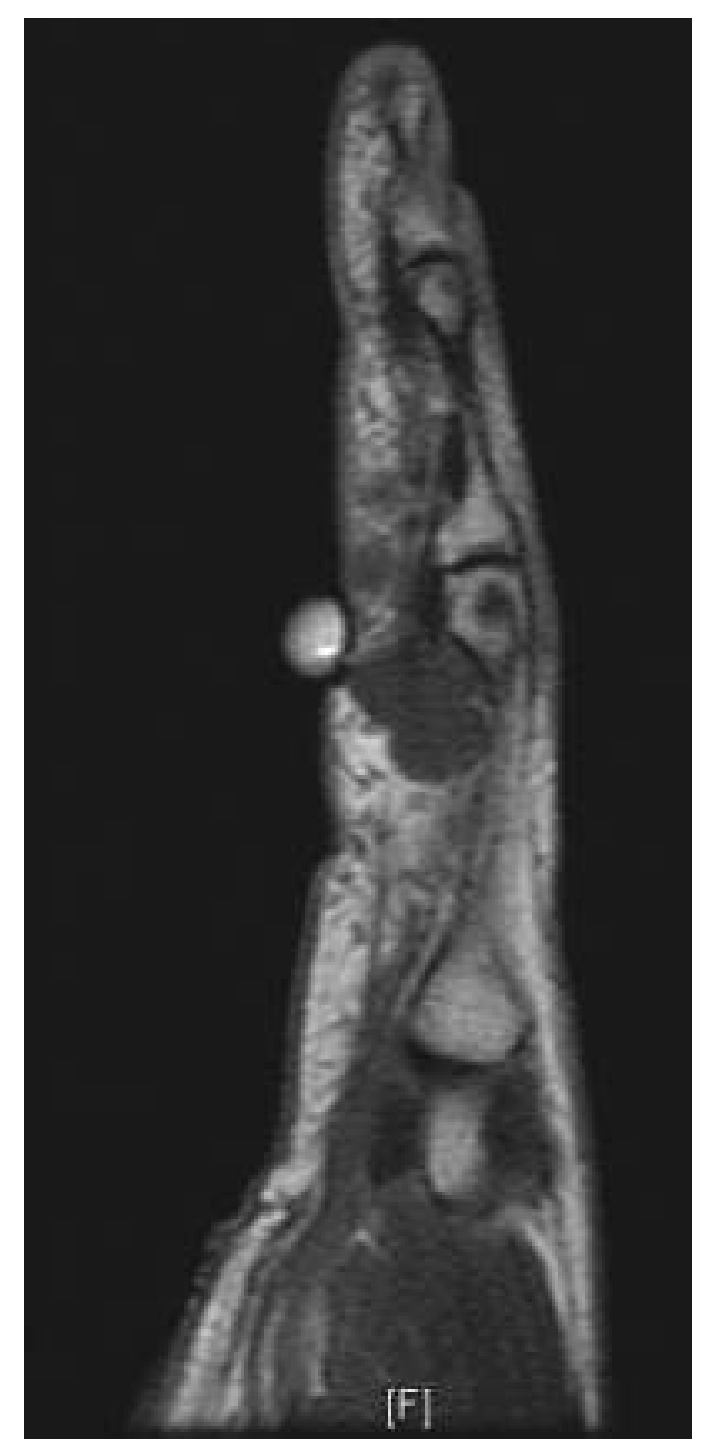

Figura 2 Sección sagital de resonancia magnética (secuencia T1) de un tumor de células gigantes de la vaina tendinosa situado en la región volar de la articulación interfalángica proximal. diferentes factores que podrían estar en relación con la posibilidad de reaparición del tumor ${ }^{17}$ : una mayor dificultad para la escisión completa de la lesión -como la localización en la zona interfalángica, sobre todo en la articulación interfalángica distal, asociada a artrosis o erosiones articulares ${ }^{18}-$, la existencia de tumores que envuelven el tendón extensor, el flexor o la cápsula $\operatorname{articular}^{19}$, o las lesiones de más de un nódulo ${ }^{20-22}$. En nuestro caso no había diferencias en la distribución del tamaño de la tumoración, la presencia de artrosis y el número de nódulos entre el grupo con y sin recidiva.

Este artículo tiene una serie de limitaciones importantes, siendo las 2 más llamativas: no haberse realizado en todos los pacientes las mismas pruebas diagnósticas y el escaso número de casos.

\section{Conclusión}

De acuerdo con nuestros resultados, la resonancia magnética tiene una capacidad diagnóstica superior a la ecografía, y esta superior a la radiografía simple, en el diagnóstico de los tumores de células gigantes de vaina tendinosa en mano. Sería adecuado realizar estudios coste-beneficio para conocer cuál sería la técnica indicada para el diagnóstico de esta patología.

El que en este análisis no sea significativa la asociación de la recidiva con ninguno de los factores valorados, no significa que no exista; puede que con la potencia de este estudio no se haya obtenido.

\section{Conflicto de intereses}

Los autores declaran no tener ningún conflicto de intereses.

\section{Bibliografía}

1. Darwwish FM, Haddad WH. Giant cell tumour of tendon sheath: Experience with 52 cases. Singapore Med J. 2008;49:879-82.

2. Uriburu IJ, Levy VD. Intraosseous growth of giant cell tumors of the tendon sheath (localized nodular tenosynovitis) of the digits: Report of 15 cases. J Hand Surg Am. 1998;23:732-6.

3. Myers VW, Masi AT. Pigmented villonodular synovitis and tenosynovitis: A clinical epidemiologic study of 166 casas and literature review. Medicine (Baltimore). 1980;59:223-38.

4. Suresh SS, Zaki H. Giant cell tumor of tendon sheath: Case series and review of literature. J Hand Microsurg. 2010;2:67-71.

5. Garg B, Kotwal PP. Giant cell tumour of the tendon sheath of the hand. J Orthop Surg (Honk Kong). 2011;19:218-20. 
6. Monaghan H, Salter DM, al-Nafussi A. Giant cell tumour of tendon sheath (localized nodular tenosynovitis): Clinicopathological features of 71 cases. J Clin Pathol. 2001;54: 404-7.

7. Kotwal PP, Fupta V, Malhotra R. Giant-cell tumour of the tendon sheath. Is radiotherapy indicated to prevent recurrence after surgery? J Bone Joint Surg. 2000;82:571-3.

8. Llauger J, Palmer J, Rosón N, Cremades R, Bagué S. Pigmented villonodular synovitis and cell tumors of the tendon sheath: Radiologic and pathologic features. AJR Am J Roentgenol. 1999;172:1087-91.

9. Gracia SDI, Succi G, Fraggetta F, Perrotta RE. Giant cell tumor of tendon sheath: Study of 64 cases and review of literature. G Chir. 2013;34:149-52.

10. Cheng JW, Tang SF, Yu TY, Chou SW, Wong AM, Tsai WC. Sonographic features of soft tissue tumors in the hand and forearm. Chang Gung Med J. 2007;30:547-54.

11. Lautenbach M, Kim S, Millrose M, Eisenschenk A. Nodular giant cell tumour of the tendon sheath of the hand: Analysis of eighty-four cases: Diagnostic decisions and outcome. Int Orthop. 2013;37:2211-5.

12. Middleton WD, Pattel V, Teefey SA, Boyer MI. Giant cell tumors of the tendon sheath: Analysis of sonographic findings. AJR Am J Roentgenol. 2004;183:337-9.

13. Wang Y, Tang J, Luo Y. The value of sonography in diagnosing giant cell tumors of the tendon sheath. J Ultrasound Med. 2007;26:1333-40.
14. Kim SH1, Kang BJ, Choi BG, Choi JJ, Lee JH, Song BJ, et al. Radiologists' performance for detecting lesions and the interobserver variability of automated whole breast ultrasound. Korean J Radiol. 2013;14:154-63.

15. Wan JM, Magarelli N, Peh WC, Guglielmi G, Shek TW. Imaging of giant cell tumour of the tendon sheath. Radiol Med. 2010;115:141-51.

16. Wang CS, Duan Q, Xue YJ, Huang XM, Wang LL, Chen ZY, et al. Giant cell tumour of tendon sheath with bone invasion in extremities: Analysis of clinical and imaging findings. Radiol Med. 2015;120:745-52.

17. Reilly KE, Stern PJ, Dale JA. Recurrent giant cell tumors of the tendon sheath. J Hand Surg. 1999;24:1298-302.

18. Al-Qattan MM. Giant cell tumors of tendon sheath: Classification and recurrence rate. J Hand Surg Br. 2001;26:72-5.

19. Williams J, Hodari A, Janevski P, Siddiqui A. Recurrence of giant cell tumors in the hand: A prospective study. J Hand Surg Am. 2010;35:451-6.

20. Grover R, Grobbelaar AO, RichmanPI, Smith PJ. Measurement of invasive potential provides an accurate prognostic marker for giant cell tumor of tendon sheath. J Hand Surg. 1998;23:728-31.

21. Fotidias E, PapadopoulosA, Svarnas T, Akritopoulos P, Sachinis NP, Chalidis BE. Giant cell tumours of the tendon sheath of the digits. A systematic review. Am Ass Hand Surg. 2011;6:244-9.

22. Wang JP, Rancy SK, diCarlo EF, Wolfe SW. Recurrent pigmented villonodular synovitis and multifocal giant cell tumor of the tendon sheath: Case report. J Hand Surg Am. 2015;40:537-41. 